\title{
Effect of Semi-synthetic Andrographolide Analogue-loaded Polymeric Micelles on HN22 Cell Migration
}

\author{
Teeratas KANSOM ${ }^{1}$, Rungnapha SAEENG ${ }^{2}$, Tanasait NGAWHIRUNPAT ${ }^{\mathbf{1}}$, \\ Theerasak ROJANARATA ${ }^{1}$, Prasopchai TONGLAIROUM ${ }^{1}$, \\ Praneet OPANASOPIT ${ }^{1}$ and Purin CHAROENSUKSAI ${ }^{1, *}$ \\ ${ }^{1}$ Faculty of Pharmacy, Silpakorn University, Nakhon Pathom 73000, Thailand \\ ${ }^{2}$ Department of Chemistry, Faculty of Science, Burapha University, Chonburi 20131, Thailand
}

('Corresponding author's e-mail: charoensuksai_p@su.ac.th)

Received: 24 May 2018, Revised: 29 October 2018, Accepted: 29 November 2018

\begin{abstract}
Semi-synthetic andrographolide (AG) analogue, namely 19-tert-butyldiphenylsilyl-8,17-epoxy andrographolide, or 3A.1, is an anticancer drug. However, the major problem of 3A.1 is poor water solubility hindering its clinical applications. To improve the water solubility and anticancer potency of this analogue, 3A.1-loaded polymeric micelles employing $N$-naphthyl- $N$ - $O$-succinyl chitosan (NSCS) as amphiphilic copolymer were prepared by the dropping method. The morphology, particle size, entrapment efficiency $(\% \mathrm{EE})$, and loading capacity $(\% \mathrm{LC})$ were evaluated. The 3A.1-loaded NSCS micelles were successfully prepared. These micelles were nano-size $(66.26$ to $102.53 \mathrm{~nm})$ and with a spherical shape, with negative surface charge $(-30.50$ to $-22.23 \mathrm{mV})$. The $3 \mathrm{~A} .1$-loaded NSCS micelles with $40 \%$ drug loading exhibited the maximum values of both \%EE $(90.84 \%)$ and \%LC (25.95\%), indicating that a high amount of 3A.1 could be entrapped into the NSCS micelles. In addition, in vitro anticancer activity and cell migration assay on HN22 cells were evaluated. The 3A.1-loaded NSCS micelles exhibited stronger anticancer effect and cell migration suppression than the free drug. Therefore, these NSCS micelles containing 3A.1 may be potential nanocarriers for the treatment of oral cancer.
\end{abstract}

Keywords: Andrographolide analogue, polymeric micelles, cell migration, oral cancer

\section{Introduction}

Head and neck cancers are common cancers that involve epithelial malignancies of the mouth, nasal cavity, pharynx, and larynx and represent about $6 \%$ of all cancer cases around the world [1]. Oral cancer with squamous cell carcinoma (OSCC) is the most common type of cancer at the head and neck regions. Currently, despite advances in multimodality treatments such as surgery, radiation, and chemotherapy for oral cancer, the incidence has continually increased, because this cancer is an aggressive epithelial malignancy with poor prognosis and a low survival rate. In advanced stage OSCC patients, there is high occurrence of metastasis to distant organs resulting in treatment failure, which is the leading cause of death $[2,3]$. Therefore, the discovery and development of effective anticancer agents from natural sources has been studied for oral cancer therapy.

Plant-derived anticancer compounds have recently been developed to treat cancer diseases. Angropholide (AG) (Figure 1a), a major diterpenoid lactone in Andrographis paniculata Nees (Acanthaceae), is used as a traditional herbal medicine in many countries, including India, China, and Southeast Asian countries (Thailand, Malaysia, Indonesia). It has been reported to have a wide spectrum of pharmacological effects, including anticancer activity [4]. However, AG lacks selectivity and potency in terms of several cancer cell lines. In order to improve cytotoxic activity to be a potential anticancer 
http://wjst.wu.ac.th

drug, many researches have attempted to chemically modify this compound [5]. In a recent research, a novel semi-synthetic AG analogue, namely 19-tert-butyldiphenylsilyl-8,17-epoxy AG, or 3A.1 (Figure 1b), was successfully synthesized. This analogue possessed potent cytotoxic activity against several cancer cells, including HepG2 (hepatocellular carcinoma), Hela (cervical carcinoma), and UISO-BCA1 (human breast carcinoma) in an in vitro testing [6]. Despite greater anticancer activity compared to the parent compound, the poor aqueous solubility of 3A.1 is one of the major problems in the delivery of the drug to targeted cancer cells, limiting its therapeutic usage. To address these problems, usage of nanocarrier-based delivery systems is a favorable approach due to their unique properties, such as nanometer size, increase in water solubility, improvement in tumor targeting, and minimization of toxicity to normal cells [7]. Polymeric micelles (PMs) have received much attention for anticancer drug delivery. PMs are spherical shaped, nanosized systems resulting from a self-assembly of amphiphilic polymers with core-shell structures. PMs could efficiently entrap hydrophobic drugs into the inner core to solubilize hydrophobic drugs, whereas the outer shell provides compatibility with the aqueous environment and helps decrease uptake by the reticuloendothelial system. In addition, $\mathrm{N}$-naphthyl- $\mathrm{N}-\mathrm{O}$ succinyl chitosan (NSCS) as an amphiphilic polymer has been used in previous work due to favorable properties including non-toxicity, biocompatibility, and biodegradability [8]. The present study aimed to encapsulate 3A.1 into NSCS PMs using the dropping method to improve aqueous solubility. Morphology, size, and drug loading were investigated. Moreover, the anticancer activity and inhibition of cell migration on OSCC cells in vitro were also studied.
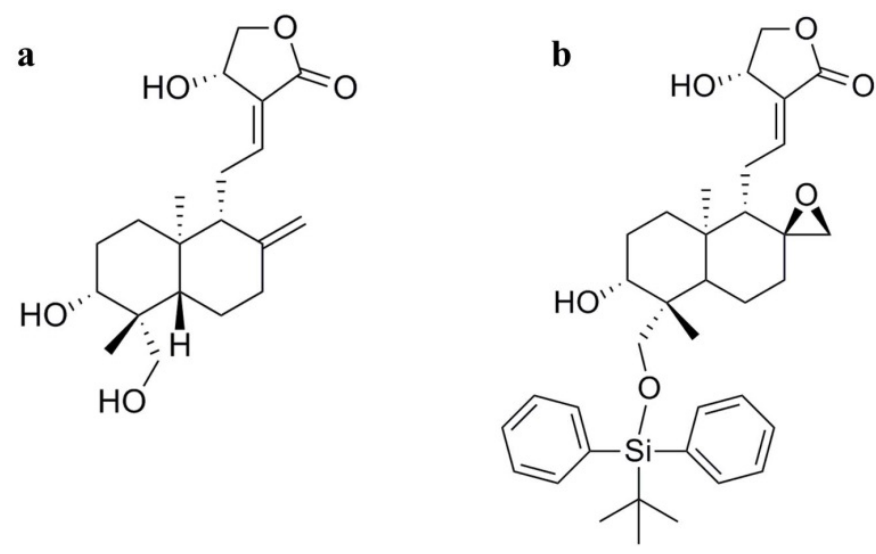

Figure 1 Chemical structure of (a) andrographolide and (b) andrographolide analogue 3A.1

\section{Materials and methods}

\section{Materials}

The 3A.1 anticancer agent was provided by Department of Chemistry, Faculty of Science, Burapha University. $\mathrm{N}$-naphthyl- $\mathrm{N}$-O -succinyl chitosan (NSCS) was synthesized and characterized by Dr. Warayuth Sajomsang (National Nanotechnology Center (NANOTEC), Thailand) [8]. Dulbecco's modified Eagle's medium (DMEM), fetal bovine serum (FBS), trypsin-EDTA, and penicillinstreptomycin were purchased from Gibco BRL (Rockville, MD, USA). All chemical substances were of analytical grade and used without further purification.

\section{Preparation of 3A.1-loaded polymeric micelles}

The NSCS PMs were prepared through the dropping method. Briefly, 3A.1 (0 - $40 \mathrm{wt} \%$ to polymer) and $5 \mathrm{mg}$ of NSCS were dissolved in $0.5 \mathrm{~mL}$ DMSO. The solution was gradually dropped into stirred water, and the mixed solution was stirred overnight. The final ratio of DMSO:water was fixed at 1:5 by 
http://wjst.wu.ac.th

volume. Subsequently, the mixture was placed in a dialysis bag and dialyzed against water overnight. The solution was centrifuged at $1,500 \mathrm{rpm}$ for $2 \mathrm{~min}$. Then, the supernatant was collected for further investigation.

\section{Characterization of 3A.1-loaded polymeric micelles}

The morphology of the blank and 3A.1-loaded NSCS PMs was observed by transmission electron microscopy (TEM, Philips ${ }^{\circledR}$ Model TECNAI 20). The particle size, polydispersity index (PDI), and zeta potential of the micelles were measured by a particle size analyzer (ZetasizerNano ZS, Malvern Instruments, UK) at $25^{\circ} \mathrm{C}$. The measurements were performed in triplicate.

\section{Entrapment efficiency (\%EE) and loading capacity (\%LC)}

The amount of the drug incorporated into the PMs was determined using an HPLC. For destabilization of the micelle structure, the 3A.1-loaded NSCS PMs were dissolved in a mixture solution of $\mathrm{DMSO} /$ water $(9 / 1, \mathrm{v} / \mathrm{v})$. The entrapped drug was quantified using a reverse-phase high performance liquid chromatography (RP-HPLC, Agilent 1100, USA) with a C-18 column $(250 \times 4.60 \mathrm{~mm}, 5 \mu \mathrm{m}$ particle size) and detected by a UV detector at $219 \mathrm{~nm}$. The mobile phase was methanol/water $(80 / 20$, $\mathrm{v} / \mathrm{v}$ ) with a flow rate of $1.0 \mathrm{~mL} / \mathrm{min}$. The $\% \mathrm{EE}$ and $\% \mathrm{LC}$ were calculated according to Eqs. (1) and (2), respectively;

Entrapment efficiency $(\%)=\left(\mathrm{C}_{\mathrm{a}} / \mathrm{C}_{\mathrm{i}}\right) \times 100$,

Loading capacity $(\%)=\left[\mathrm{C}_{\mathrm{a}} /\left(\mathrm{C}_{\mathrm{i}}+\mathrm{L}_{\mathrm{i}}\right)\right] \times 100$,

where $C_{a}$ is the amount of 3A. 1 in the NSCS micelles, $C_{i}$ is the initial amount of $3 \mathrm{~A} .1$ in micelles, and $\mathrm{L}_{\mathrm{i}}$ is the amount of NSCS used for the micelle formulations.

\section{In vitro anticancer activity}

The effect of the free drug and the drug-loaded NSCS PMs on the cell viability of HN22 cells were studied by MTT assay [8]. The cells were seeded in 96-well plates at 60 - $70 \%$ confluency in DMEMcontaining serum. Afterwards, the cells were treated with $3 \mathrm{~A} .1$ and the $3 \mathrm{~A} .1$-loaded micelles with drug concentrations of 0.1 to $10.0 \mu \mathrm{g} / \mathrm{mL}$, followed by incubation at $37{ }^{\circ} \mathrm{C}$ in a $\mathrm{CO}_{2}$ incubator for $24 \mathrm{~h}$. After that, MTT solution in PBS $(5 \mathrm{mg} / \mathrm{mL})$ was added to each well, and the cells were then further incubated for $4 \mathrm{~h}$. Then, $100 \mu \mathrm{L}$ DMSO was added to solubilize the formed formazan crystals. The plates were then incubated in the dark at $37{ }^{\circ} \mathrm{C}$ for $30 \mathrm{~min}$, and the absorbance at $550 \mathrm{~nm}$ was measured using a microplate reader (Universal Microplate Analyzer, Model AOPUS01 and AI53601, Packard BioScience, CT, USA).

\section{In vitro cell migration}

In vitro scratch assay was performed for the assessment of cell migration due to it being a simple, inexpensive, and well-developed method [9,10]. Briefly, the HN22 cells were cultured in 6-well plates until confluent as a monolayer. To create a gap in the cell monolayer, a uniform gap (about 1,000 $\mu \mathrm{m}$ ) was scratched from edge-to-edge in each well using a sterile $200-\mu \mathrm{L}$ pipet tip to generate 3 straight lines/well. The cells were washed gently with $1.0 \mathrm{~mL}$ PBS to remove the detached cell and residual media. Both 3A.1 and the 3A.1-loaded micelles at a final concentration of $3.0 \mu \mathrm{g} / \mathrm{mL}$ in serum free DMEM were added into each well, and then incubated at $37^{\circ} \mathrm{C}$ in a $\mathrm{CO}_{2}$ incubator for $24 \mathrm{~h}$. The images of the wound were taken using an inverted microscope (Model: T-DH Nikon ${ }^{\circledR}$, Japan) at 0, 6, 10, 18, and $24 \mathrm{~h}$. The image was captured by 3 images/well/time point, and the wound gap and wound area were determined using ImageJ software (National Institutes of Health) using 40× magnification. \%wound closure was calculated according to Eq. (3); 
http://wjst.wu.ac.th

$\%$ Wound closure $=\left[\frac{\text { wound area at start time }- \text { wound area at end time }}{\text { wound area at start time }}\right] \times 100$.

\section{Statistical analysis}

All experiments were performed in triplicate. All results are expressed as mean $\pm \mathrm{SD}$. The independent sample t-test was used and the one-way analysis of variance (ANOVA) and the Tukey multiple comparison were used for analysis of statistical difference between groups using GraphPad Prism version 5.01 (GraphPad, Inc, USA). P values $<0.05$ are considered as statistically significant differences.

\section{Results and discussion}

Preparation and characterization of the blank micelles and the 3A.1-loaded micelles

The NSCS was used as an amphiphilic graft copolymer for the polymeric micelle formulations. This is composed of a hydrophobic naphthyl and a hydrophilic succinyl group that can entrap hydrophobic anticancer drug 3A.1 into the core-shell structure of PMs. In this research, the dropping method, as one of the simplest and most convenient physical preparation methods, was selected to prepare the blank micelles and the 3A.1-loaded NSCS PMs. The TEM image of the blank micelles and the $40 \% 3 \mathrm{~A} .1$ loaded NSCS PMs prepared by the dropping method are presented in Figure 2. The TEM image revealed that the formed particles were of spherical shape and of nanometer size.
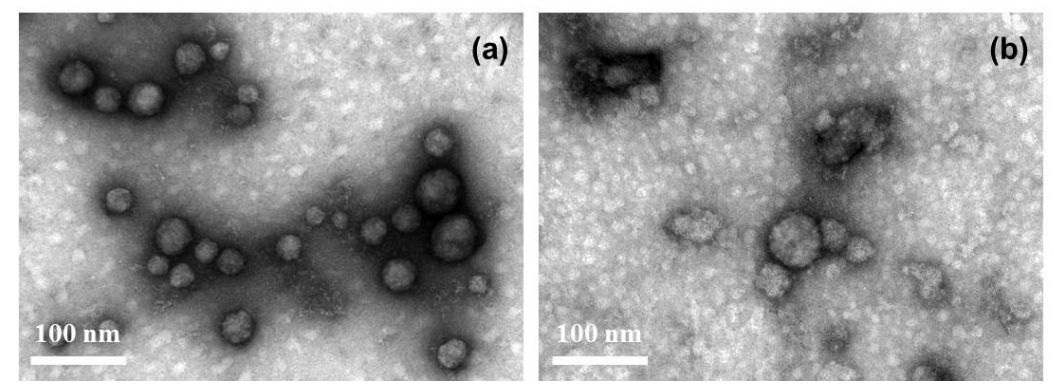

Figure 2 TEM images of the NSCS micelles. (a) Blank NSCS PMs and (b) $40 \%$ 3A.1-loaded NSCS PMs

The particle size, PDI, and zeta potential of the blank micelles and the 3A.1-loaded NSCS PMs are shown in Table 1. The size of the drug-loaded PMs was larger than that of the blank PMs due to drug encapsulation. The micelle size of the drug-loaded PMs increased with an increase in the drug to polymer ratio. These micelles had mean particle sizes of less than $200 \mathrm{~nm}$, with narrow size distributions. The 3A.1 molecule could form interactions with the hydrophobic cores of NSCS PMs by hydrophobichydrophobic bonding. The zeta potential of both the blank micelles and the drug-loaded PMs were electrically negative charges that could prevent particle aggregation.

\section{Drug loading}

The entrapment efficiency (\%EE) and loading capacity (\%LC) of the drug-loaded NSCS PMs are summarized in Table 1. The results showed that different drug concentrations affected the $\% \mathrm{EE}$ and $\% \mathrm{LC}$, since both the \%EE and \%LC values increased with an increase in drug to polymer ratio. The entrapment mechanisms of 3A.1-loaded micelles were likely due to the hydrophobic interaction between aromatic groups of 3A.1 molecules and the hydrophobic inner core (naphthyl group) of the polymers, as suggested by previous reports regarding the incorporation behaviors of meloxicam [11]. Noticeably, the 
http://wjst.wu.ac.th

$40 \% 3$ A.1-loaded NSCS PMs showed the highest \%EE $(90.84 \pm 3.34)$ and $\% \mathrm{LC}(25.95 \pm 1.48)$. Thus, this formulation was selected for further evaluation.

We tried to study the solubility of free 3A.1 in water; unfortunately, we could not detect the amount of 3A.1by HPLC, indicating that free 3A.1 had poor water solubility, at least below the detection limit of our HPLC $(1 \mu \mathrm{g} / \mathrm{mL})$. However, when 3A.1 was entrapped in the micelles, HPLC readily reported the 3A.1 peak, with a 3A.1 concentration range from $\sim 400$ to $450 \mu \mathrm{g} / \mathrm{mL}$. This result revealed that the micelle system could dramatically increase aqueous solubility of this drug, and highlights micelle preparation as an effective carrier for the aqueous solubility enhancement of 3A.1.

Table 1 Characteristics of blank and 3A.1-loaded NSCS PMs. Each data is presented as the mean \pm SD (n $=3)$

\begin{tabular}{cccccc}
\hline $\begin{array}{c}\text { 3A.1 } \\
\text { (\% to polymer) }\end{array}$ & $\begin{array}{c}\text { Particle size } \\
(\mathbf{n m})\end{array}$ & PDI & $\begin{array}{c}\text { Zeta potential } \\
(\mathbf{m V})\end{array}$ & \%EE & \%LC \\
\hline 0 & $66.26 \pm 1.21$ & 0.300 & $(-)) 30.50 \pm 1.93$ & - & - \\
5 & $75.23 \pm 1.35$ & 0.164 & $(-) 26.77 \pm 0.97$ & $46.95 \pm 2.62$ & $2.24 \pm 0.12$ \\
10 & $82.12 \pm 3.55$ & 0.185 & $(-) 28.80 \pm 2.32$ & $57.49 \pm 0.80$ & $5.23 \pm 0.08$ \\
20 & $90.33 \pm 2.28$ & 0.255 & $(-) 24.97 \pm 1.11$ & $72.59 \pm 3.61$ & $12.10 \pm 0.93$ \\
40 & $102.53 \pm 0.60$ & 0.162 & $(-) 22.23 \pm 5.27$ & $90.84 \pm 3.34$ & $25.95 \pm 1.48$ \\
\hline
\end{tabular}

$* \%$ to polymer is defined as amount of drug, calculated based on $5 \mathrm{mg}$ of polymer $(\% \mathrm{~W} / \mathrm{W})$

\section{In vitro anticancer activity}

The cytotoxic activity of the $40 \%$ 3A.1-loaded NSCS PMs and free 3A.1 were evaluated against HN22 cells using MTT assay. As shown in Figure 3, the different concentrations of the free drug and the drug-loaded PMs exhibited anticancer activity against HN22 cells in a dose-dependent manner. The results revealed that $\mathrm{IC}_{50}$ of the drug-loaded PMs $(3.04 \pm 1.20 \mu \mathrm{g} / \mathrm{mL})$ was slightly lower than the $\mathrm{IC}_{50}$ of the free drug $(4.65 \pm 1.35 \mu \mathrm{g} / \mathrm{mL})$, but the difference was not statistically significant $(p>0.05)$. This data indicated that the drug-loaded NSCS PMs still retained growth inhibition against HN22 cells when compared to the free drug. 
http://wjst.wu.ac.th

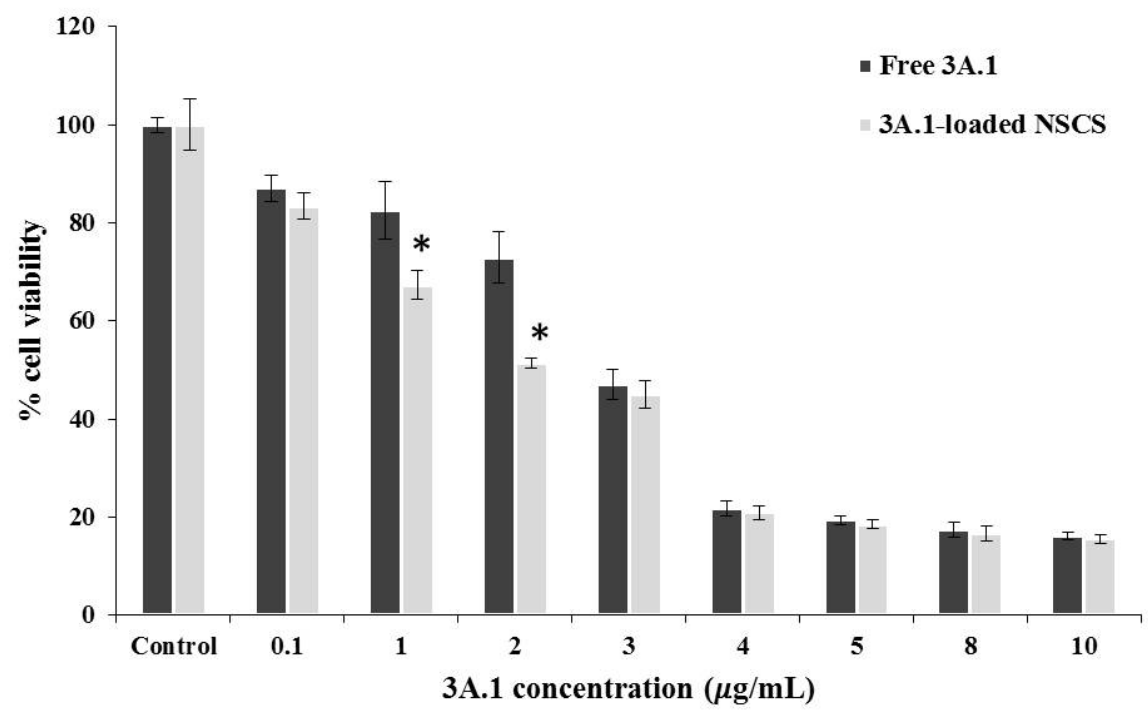

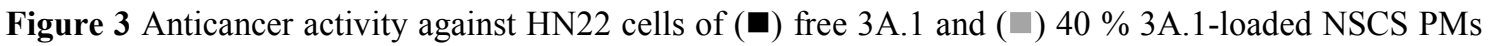
determined by MTT assay. Each value presents the mean $\pm \mathrm{SD}$ of 5 replications. $\mathrm{IC}_{50}$ values were estimated using GraphPad Prism v. 5.01 and their values present the mean \pm SD of 3 replications. *, $p<$ 0.05 compare free 3A.1 at the same concentration.

\section{In vitro cell migration}

As revealed in many reports, the parent compound AG exhibits anti-migratory activity against several human cancer cell lines [12], such as breast cancer cell line MDA-MB-231 [13], non-small cell lung cancer cell line A549 [14], and colon cancer cell lines CT26 and HT29 [15]. Additionally, some AG derivatives were reported to suppress cell migration in cancer cell lines [12]. For example, Hsieh et al. demonstrated that dehydroandrographolide inhibited cell migration in SCC9 oral cancer cell lines [16]. However, the anti-migratory effect of 3A.1 analogue has not been studied in cancer cells. Here, we have unprecedentedly revealed the anti-migratory activity of $3 \mathrm{~A} .1$ through an in vitro scratch assay compared to the free drug dissolved in DMSO. In this study, the images expressing wound gap in each treatment at $0,6,10$, and $18 \mathrm{~h}$ are shown in Figure 4a. For the quantification of cell migration, the \%wound closure is presented in Figure 4b. The \%wound closure was not significantly different in the control and DMSO groups, indicating that at $0.1 \%$ DMSO did not interfere with the migration of HN22 cells. The drugloaded PMs exhibited significantly slower wound closure rates compared to the free drug $(p<0.05)$. This finding suggested that the formulation of anticancer drug 3A.1 into NSCS PMs increased the migration suppression of 3A.1 against HN22 cells compared to the free drug. This result was consistent with previous studies, which reported that curcumin-loaded methoxy polyethylene glycol-polylactide polymeric micelles can significantly suppress migration of human A549 non-small-cell lung cancer at a higher rate than the free drug [12]. Another study confirmed that the inhibitory migration effect of fisetin as anticancer drug-loaded tocopheral polyethylene glycol 1000-polylactide polymeric micelles against MCF breast cancer cells was better than that of the free drug [13]. 

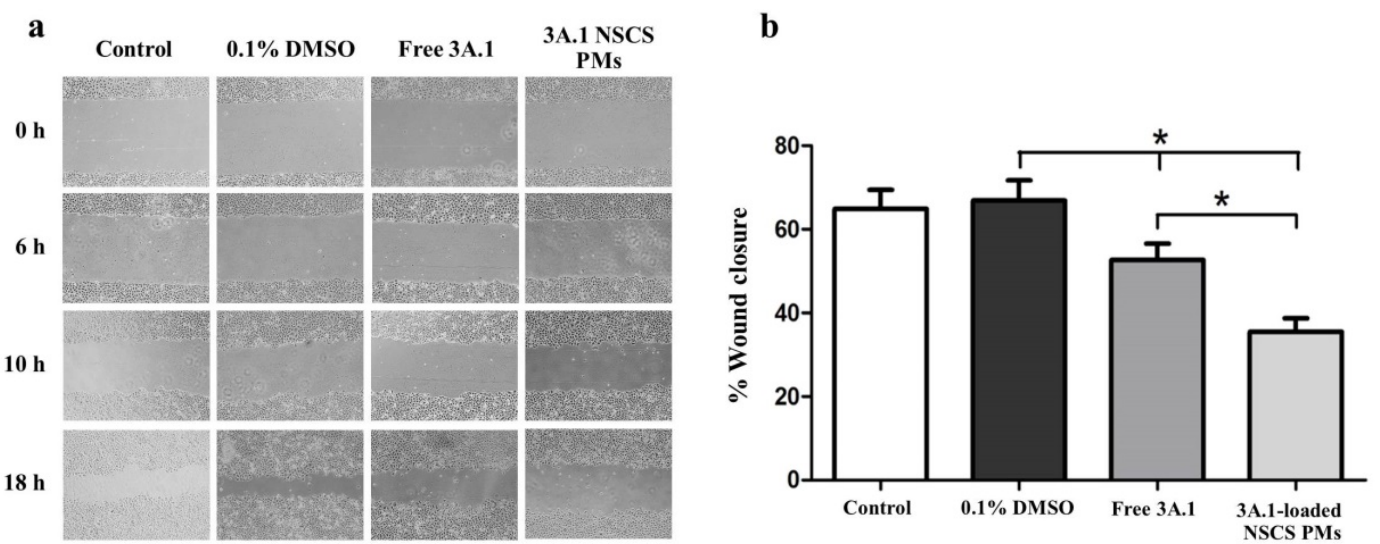

Figure 4 The $40 \%$ 3A.1-loaded NSCS suppressed cell migration in scratch assay compared to free 3A.1 (equivalent concentration) in HN22 cells. (a) The images of wound gap of each treatment at various time points. (b) \%wound closure of each condition at $18 \mathrm{~h}$ time point. $*, p<0.05$ denotes statistically significant difference compared with other groups.

\section{Conclusions}

3A.1-loaded NSCS PMs were successfully prepared through the dropping method. These PMs had small particle size with high drug loading. Moreover, the drug-loaded PMs not only enhanced anticancer activity against OSCC cells, but also potentiated inhibitory activity toward HN22 cell migration in vitro compared to the free drug. This study suggests that the 3A.1-loaded NSCS PMs may be promising nanocarriers for oral cancer chemotherapy. However, further in vitro cell migration is needed to be tested in other cancer cell lines. Moreover, the performance of this micelle delivery system should be evaluated using an appropriate animal model.

\section{Acknowledgements}

The authors gratefully thank the Commission of Higher Education (Thailand), the Thailand Research Fund through the Golden Jubilee Ph.D. Program (Grant No. PHD/0077/2558), and the International Research Network Fund (IRN58W0004) for their financial support.

\section{References}

[1] J Noguti, CFD Moura, GPD Jesus, VHD Silva, TA Hossaka, CT Oshima and DA Ribeiro. Metastasis from oral cancer: An overview. Cancer. Genom. Proteom. 2012; 9, 329-36.

[2] D Sano and JN Myers. Metastasis of squamous cell carcinoma of the oral tongue. Cancer Metastasis. Rev. 2007; 26, 645-62.

[3] S Irani. Distant metastasis from oral cancer: A review and molecular biologic aspects. J. Int. Soc. Prev. Commun. Dent. 2016; 6, 265-71.

[4] MS Hossain, Z Urbi, A Sule and KM Rahman. Andrographis paniculata (Burm. f.) Wall. ex Nees: A review of ethnobotany, phytochemistry, and pharmacology. Sci. World. J. 2014; 2014, 274905.

[5] U Sirion, S Kasemsook, K Suksen, P Piyachaturawat, A Suksamrarn and R Saeeng. New substituted C-19-andrographolide analogues with potent cytotoxic activities. Biorg. Med. Chem. Lett. 2012; 22, 49-52.

[6] J Nateewattana, R Saeeng, S Kasemsook, K Suksen, S Dutta, S Jariyawat, A Chairoungdua, A Suksamrarn and P Piyachaturawat. Inhibition of topoisomerase II alpha activity and induction of 
apoptosis in mammalian cells by semi-synthetic andrographolide analogues. Invest. New Drugs 2013; 31, 320-32.

[7] P Kumari, G Glosh and S Biswas. Nanocarriers for can-targeted drug delivery. J. Drug Target 2016; 24, 179-91.

[8] W Sajomsang, P Gonil, S Saesoo, U Raktanonchai, W Srinuanchai and S Puttipipatkhachorn. Synthesis and anticervical cancer activity of novel $\mathrm{pH}$ responsive micelles for oral curcumin delivery. Int. J. Pharm. 2014; 477, 261-72.

[9] C Liang, AY Park and JL Guan. In vitro scratch assay: A convenient and inexpensive method for analysis of cell migration in vitro. Nat. Protoc. 2007; 2, 329-33.

[10] A Grada, M Otero-Vinas, F Prieto-Castrillo, Z Obagi and V Falanga. Research techniques made simple: analysis of collective cell migration using the wound healing assay. J. Invest. Dermatol. 2016; 137, e11-e16.

[11] T Woraphatphadung, W Sajomsang, P Gonil P, A Treetong, P Akkaramongkolporn, T Ngawhirunpat and P Opanasopit. pH-Responsive polymeric micelles based on amphiphilic chitosan derivatives: Effect of hydrophobic cores on oral meloxicam delivery. Int. J. Pharm. 2016; 497, 15060 .

[12] MT Islam, ES Ali ES, SJ Uddin, MA Islam, S Shaw, IN Khan, SSS Saravi, S Ahmad, S Rehman, VK Gupta, MA Găman, AM Găman, S Yele, AK Das, JMCE Sousa, SMMM Dantas, HML Rolim, AAC Melo-Cavalcante, MS Mubarak, NS Yarla, JA Shilpi, SK Mishra, AG Atanasov and MA Kamal. Andrographolide, a diterpene lactone from Andrographis paniculata and its therapeutic promises in cancer. Cancer Lett. 2018; 420, 129-45.

[13] Z Zhai, X Qu, H Li, Z Ouyang, W Yan, G Liu, X Liu, Q Fan, T Tang, K Dai and A Qin. Inhibition of MDA-MB-231 breast cancer cell migration and invasion activity by andrographolide via

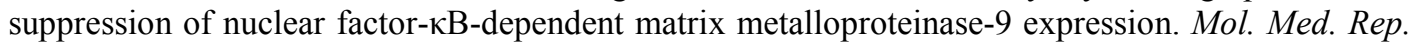
2015; 11, 1139-45.

[14] YC Lee, HH Lin, CH Hsu, CJ Wang, TA Chiang and JH Chen. Inhibitory effects of andrographolide on migration and invasion in human non-small cell lung cancer A549 cells via down-regulation of PI3K/Akt signaling pathway. Mol. Cell. Pharmacol. 2010; 632, 23-32.

[15] HP Chao, CD Kuo, JH Chiu and SL Fu. Andrographolide exhibits anti-invasive activity against colon cancer cells via inhibition of MMP2 activity. Planta. Med. 2010; 76, 1827-33.

[16] MJ Hsieh, JC Chen, We Yang, SY Chien, MK Chen, YS Lo, YT Hsi, YC Chuang, CC Lin, and SF Yang. Dehydroandrographolide inhibits oral cancer cell migration and invasion through NF-кB-, AP-1-, and SP-1-modulated matrix metalloproteinase-2 inhibition. Biochem. Pharmacol. 2017; 130, $10-20$.

[17] WT Zhu, SY Liu, L WU, HL Xu, J Wang, GX Ni and QB Zeng. Delivery of curcumin by directed self-assembled micelles enhances therapeutic treatment of non-small-cell lung cancer. Int. J. Nanomed. 2017; 12, 2621-34.

[18] L Wang, DZ Zhang and YX Wang. Bioflavonoid fisetin loaded $\alpha$-tocopherol-poly(lactic acid)based polymeric micelles for enhanced anticancer efficacy in breast cancers. Pharm. Res. 2017; 34, 453-61. 